\title{
AS CIÊNCIAS NATURAIS E A CONSTRUÇÃO DA NAÇÃO BRASILEIRA ${ }^{1}$
}

\author{
Heloisa M. Bertol Domingues \\ Doutora pelo DH-FFLCH/USP
}

\begin{abstract}
RESUMO: Este artigo aborda as relações entre as ciências naturais e a política do governo imperial brasilciro, nas décadas de meados do século XIX, mostrando que estas relaçōes contribuiram para consolidar a integraçāo territorial do país sob a égide da ideologia da nação. Para realizar seus propósitos o governo incentivou o movimento de exploração da naturcza, organizando e implementando comissões científicas que se dirigiram a diferentes lugares do país para estudar a sua geografia, gcologia, botânica, zoologia. astronomia c a sua ecnołogia. Esta política transformaria o meio ambiente brasileiro $\mathrm{em}$ objeto político, bem como valorizaria enormemente as ciências naturais, propiciando até mesmo a institucionalizą̧ão de novos ramos destas no país.
\end{abstract}

ABSTRACT: This article broaches the relations between natural sciences and the Brazilian imperial government's policy undertaken during the mid-1800s in order to consolidate national unity. To accomplish such a purpose, the government encouraged the exploration of the country's hinterland by organizing and sending scientific commissions to different regions of the country to study its geography, geology, botany, zoology, astronomy, and ethnology. Besides regarding Brazil's nature as a political object, this policy emphasized the rolc of natural sciences in the country and the institutionalized some of their branches.

PALAVRAS-CHAVE: Brasil, século XIX, ciências naturais, política agrícola, comissōes científicas

KEYWORDS: Brazil, 19th century, natural sciences, agrarian policies, scientific commissions

No Brasil, o processo da construção política e ideológica da nação teve estreita relação com aque-

I. Este trabalho, parte de minha tese de doutoramento - $\mathrm{Ci}$ ência: un caso de polírica. As relaçöes entre as Ciências Nalurais e a Agricultura no Brasil Império - desenvolvida no Departamento de História. FFLCH-USP, contou com o financiamento
Ic da institucionalização das ciências naturais. Nação, que inicialmente tinha sido um termo usado para designar grupos sociais que apresentavam uma iden-

da Fundaçào de Amparo à Pesquisa do Estado de Săo PauloFAPESP. Foi apresentado no IV Congresso Latino A Anericano de História das Ciências e das Técnicas, Cali. Colômbia. 1995. 
tidade comum, como por exemplo as tribos indígenas consideradas exóticas, no século XIX foi confundida à noção de Estado e encampada pelas políticas dos Estados que se organizavam e almejavam tornar-se Estados nacionais (PLUMYĖNE, 1979; CELLARD, 1979; FURET, 1982). O Brasil, depois da independência política em 1822, foi parte integrante daquele processo de construção do EstadoNaçāo.

Entretanto, as resistências internas e externas que o governo enfrentou ao instalar-se em 1822 impediram a complementação do processo de unidade política em torno da monarquia cujo objetivo, em última instância, cra a instalação de um império nacional. Império que somente se consolidou $\mathrm{cm}$ meados do século, quando as lutas internas foram sufocadas, dirimindo as diferenças regionais e quando o fim do

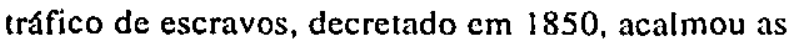
turbulências externas, principalmente com a Inglaterra que não tolerava a persistência da escravidão no Brasil e o pressionou como pode. Ora, num país cuja economia pautava-se na agro-exportação, a manutenção de boas relações com o exterior eram sobremaneira importantes.

A economia brasileira era uma herança colonial que o governo imperial optou por manter e aprofundar a tal ponto que o país veria toda a sua estrutura econômica associada à agricultura. Porém, a agricultura de exportação do Brasil que nas primciras decadas do século XIX em alguns momentos sobrepujou as economias concorrentes como, por exemplo, a dos Estados Unidos da América do Norte, aos poucos foi perdendo o terreno e, enquanto o volume das exportações americanas se multiplicava, o do Brasil passou apenas a somar apenas algumas tibras (SIMONSEN, 1978).

Em meados do sćculo, o Estado brasileiro organizado em torno do poder monárquico de D.Pedro II, passou a emprecnder uma política que viesse ao mesmo tempo, dar bases à sua identidade nacional e impulso à sua economia. Foi inserido naquela conjuntura sócio-política que estruturou-se também o movimento romântico nacional e as ciências naturais ganharam largo reconhecimento por parte do poder político. A idéia de naçāo que se desenvolveu no Brasil naquela época criou uma imagem da nação associada às suas riquezas naturais: as riquezas, potencialmente econômicas que o país guardava em suas entranhas ainda inexploradas. O movimento romântico valorizou as riquezas naturais do país. fazendo-as marca da sua singularidade e símbolo da liberdade frente à espoliação que este havia sofrido da parte do colonizador metropolitano (COSTA LIMA, 1984, p.147). Por outro lado, a política que se inauguraria, nos anos 40 do século XIX, viria dar mostras que o governo havia adquirido uma visão de conjunto do país, pois, querendo assumi-lo como um todo, promoveu campanhas de povoamento e organizou comissões científicas de exploração para promover o levantamento e a consequente exploração agrícola das suas riquezas naturais ${ }^{2}$.

O governo de D.Pedro II promoveu uma espécie de marcha para o interior do país a fim de buscar naquele interior novos produtos para o comércio e, no sentido inverso, através da abertura de caminhos terrestres e fluviais, objetivava levar aos quatro cantos o povoamento e os transportes. Dir-se-ia que era uma política de recolonização do pais que o governo empreendia (DOMINGUES,1990, p.116). Em tal política, as ciências naturais ganharam novas e enormes dimensões.

2. Uma das razôes porque os inoviınentos autonomisıas surgidos na época de crise do sistema colonial haviam abortado tinha sido. segundo Marques dos Santos, a visĩo fragmentada $\mathrm{c}$ regionalizada do espaço físico do pafs que os inconfidentes demonsiraram ter (MARQUES DOS SANTOS. A.C. No Rascunho da Narcâo: Incondidência no Rio de Janeiro. Rio, Coleçāo Biblioteca Carioca,Secreteria Municipal de Cultura. Turismo e Esportes, 1992). 
Institucionalmente, estas ciências já eram prática corrente no país, realizando-se principalmente no Museu Nacional e no Jardim Bolânico da Corte, bem como numa instituição particular, a Sociedade Auxiliadora da Indústria Nacional, ou através do ensino nas escolas superiores Militar e de Medicina (DANTES, 1979/80, v.2). Em 1838, em plena conjuntura do Regresso, foi criado o Instituto Histórico e Geográfico Brasilciro (IHGB), com a finalidade de fazer a história do Brasil para dar bases à sua nacionalidadc. Para realizar o seu intento, o próprio nome indicava que a nova instituição scria coadjuvada pelas ciências naturais, particularmente pela geografia. A relaçāo da história com a geografia, além da prática científica, cvidenciava o valor ideológico $\mathrm{c}$ simbólico que adquiriu o meio ambiente do país para a política de construção da naçāo.

O conceito de geografia que operava no IHGB expressava a imbricaçāo da história e da política do governo com a exploração do meio ambiente:

O objeto da Geografia ț o estudo da superficie da terra; mas não merecera o nome de ciência se se contentasse de estudar somente as formas materiais, e os acidentes que a cobrem. A superficie da terra é teatro da atividade do homem: ela se modifica debaixo de sua açūo. e com ele estí èn uma relaçāo etema. As cmigraçōes dos povos: as descobertas, que abreviam os espaços mais distantes: as plantas e animais que servem à vida do homem, por ele transportados de um país a outro: os elementos submetidos ao seu poder: os raios obedecendo so seu chamamento: a terra cobrindo-se de cidades ...: os rios dirigidos, represados, e nāo poucas vezes tomando o curso que the traça o povo habitador das suas margens: tudo isto pertence à História, mas pertence tam-

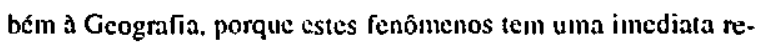
lação com o espaço, e sobre cle exerecm uma bem clara influência. (Januário da Cunha Barbosa, Revista do IHGB, 2(1840)575).

Assim, no Instituto Histórico c Gcográfico BrasiIeiro, era o avanço do homem para dominar a natureza que dava sentido tanto à história quanto à geografia. Era este mesmo processo de dominação que o governo brasileiro começava a empreender para realizar o almejado projeto de unidade territorial do país. O Brasil, situado no seio do capitalismo internacional em expansão $\mathrm{e}$, cujas relações do homem com o meio baseavam-se na exploração dos produtos naturais passíveis de valor comercial, inseria-se naquela conjuntura buscando dominar seu próprio espaço natural geográfico. A finalidade do Estado e de seus intelectuais, era elcvar a natureza do país da barbárie à civilização. Naquele momento a política brasileira de construção nacional esteve condicionada à dominação e conquista do meio natural.

A dominação do meio ambiente do país condicionava-se também ao povoamento $\mathrm{e}$, num cenário de natureza inóspida, nada melhor do que os habitantes nativos, que a conheciam, para trabalhá-la. Conforme lembrou Sérgio Buarque de Holanda, foi nos aspectos da vida material que os colonos europeus se mostraram mais acessíveis à incorporação das tradiçōes divergentes das européias e, por exemplo, o vocabulário brasileiro guardou vestígios dos termos técnicos da vida rural, bem como utilizou numerosos objetos que os mesmos vocábulos designam (HOLANDA, 1994, p.156). Esta troca de relaçōes e o aproveitamento dos índios como mão-de-obra substituta dos cscravos, parece ter contribuído para que um outro aspecto das ciências naturais, a etnografia, rapidamente ganhasse espaço institucional. Em 1847, na estrutura do mesmo Instituto Histórico e Geográrico Brasileiro foi inserida uma terceira comissão de estudo, a Comissão de Etnografia e Arqucologia Indígena cuja finalidade era verilicar o estado de civilização dos índios do país, isto é, verificar até que ponto eles se apresentavam aptos aos trabalhos agrícolas, pois, salientavam que a experiência havia mostrado que tinham aptidão para trabalhar na terra ou no mar, canto quanio os negros (J. da Cunha Barbosa, Revista do IHGB, 1 (1838), p.145-152.).

A relação desses ramos das ciências naturais com a política de construção da nação nāo ficava apenas 
ao nível institucional, do discurso ou das publicaçōes na revista do Instituto Histórico e Geográlico Brasileiro, mas realizava-se na prática, evidenciada na organização de diversas comissões científicas e viagens para o interior do país sob a proteção do governo imperial do Brasil. O próprio IHGB, cm conjunto com o governo, promoveu, em 1859, a conhecida Comissāo Cientifica para explorar o norte do Império, a região mais cobiçada $\mathrm{cm}$ termos de riquezas naturais do país. A Comissão Científica seria composta somente por brasileiros e contaria com cinco grupos de trabalhos: o de Botânica, de Geologia e Mineralogia, o de Zoologia, o de Astronomia e Geografia e o de Etnografia ${ }^{3}$. Todos cstes aspectos das ciências naturais, segundo as Instruções para a Comissāo, cabia trabalhar a fim de superar as limitaçōes que o meio ambiente impunha à exploração das riquezas nacionais.

Grosso modo pode-se dividir as atividades cientificas que engendravam a exploração do meio ambiente brasileiro em duas grandes linhas, a exploração geográfica e a ctnográfica, levando em conta que o conhecimento de terrenos e produtos era tão importante quanto o povoamento. Ambos sram condicionantes do desenvolvimento da agricultura do país, a base da sua economia.

\section{A Exploração Geográfica}

Assim, é possível pensar que as dimensões da política de interiorização cmprecndida pelo governo imperial do Brasil em meados do século XIX. seriam dadas pelas cicencias naturais $c$, especialmente pelos ramos abrangidos pela geografia, conforme a

3. Trabalhos da Comissāo Científica de Exploracăon. Rio, Typ. Universol de Laemmert, 1862. entendiam no IHGB e conforme dizia um dos seus

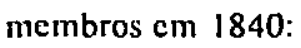

A geogrufia. nâ comtente em descrever a superficie do globo. nos fez comhecer as diversas rasas que a habitam. e nos indi. ca os lugares onde a nutureza colocon as suas variadas e excelentes porduçōes, nadu hi sobre a terra que possu fugir an exame. que possa evilur as narracies. do geoigrafot.

A geografia tinha portanto um amplo conceito, cujo estudo abrangia nāo somente os aspectos físicos dos lugares, mas incluia, como se pode inferir daquelas palavras, tanto a gcologia, a arqueologia $e$, até mesmo, a etnografía.

A expansão das fronteiras no sentido de alargar as áreas agricolamente exploradas e habitadas do Brasil, deu-se, naquela ocasião, sob a orientaçāo do poder político do Estado. O Instituto Histórico que trabalhava lado a lado ao Imperador, ainda em 1841, anunciou que, sob a proteção deste, estava criando uma Comissāo de cinco membros, que seria dirigida pelo presidente do IHGB, Visconde de São Leopoldo, para corrigir e juntar num só volume os mapas geográficos das províncias do Brasil, cuja geografia se acha desgraçadamente confusa, para não dizer ignorada, dizia J. da Cunha Barbosa (Revista do IHGB, 3 (1841)529).

O conhecimento do mapa das províncias tinha por firm facilitar as viagens que objetivavam fazer o descjado geo-reconhecimento do país. No próprio Instituto Histórico foram divulgados diversos rela-

4. SILVA PONTES, R. de S. Quais os meios de que se deve lançar mão para obter o major número possível de documentos relativos à História e Geografía do Brasil? Programa apresentado na sessão de 24 de dezembro de 1840. Revista do Instisuro Histórico e Geogrifico Brasileiro (RIHGB), 3 (184I), p.149. 
tórios de viagens que se realizaram a partir dos anos 40 do século XIX e outros mais antigos que falavam dos lugares e das relações dos europeus com os indios, e que tinham como objetivo criar os caminhos do interior e estabelecer contato com os índios, para conhecer e explorar as chamadas riquezas naturais ${ }^{3}$. As descriçōes davam conta, da navegabilidade dos rios, dos aspectos naturais tais como, correntes de ventos, condições climáticas de cada lugar, das marés e enchentes por ocasião das chuvaś, bem como dos contornos físicos das regiões que perconriam ${ }^{6}$.

O conhecimento das condições fisicas locais era importante tanto para os viajantes como para aqueles que por ventura viessem estabelecer-se nos lugares ainda inabitados. Um importante roteiro realizado no Rio Negro, um dos grandes afluentes do Amazonas, chamava atenção por exemplo, para a presença de insetos na região, dizendo que apesar da fertilidade do solo e do clima aprazivel, podiam causar problemas ${ }^{7}$. A terra se constituia porém num bom motivo para enfrentar as dificuldades. Na mes-

5. Viagem às Vilas de Carnvelas, Viçosa, Porto Alegre, de Mucury, e aos rios Mucury, e Peruhipe, realizada em 1845 (RJHGB, 8(1846)425); Relatório dirigido ao ministro de instrução pública pelo Sr. Castelnau, encarregado de uma comissão na América Meridional. Goiás, 22 de outubro de 1844. (RIHGB, 7(1845)218); Itinerário de duas viagens exploradoras cmpreendidas pelo Sr. Barão de Antonina e o Baixo Paraguai na província de Mato Grosso: feitas nos anos de 1844 a 1847 pelo sertanista o sr. Jonquim Francisco Lopes, e descritas pelo sr. João Henrique Eltiot (RIHGB, 10(1848)153-177). Notícia sobre a descoberta do campo das Palmas, realizada em 1850 (RIHGB, 14(1851) 425.

6. Diário Roteiro do Arraial do Pesqueiro d'Araguari até ao rio Ouyapoko, pelo capitão Manoel Joaquim de Abrets. RJHGB, 12(1850)98.

7. Noticias Geográficas da capitania do Rio Negro no grande Rio Amazonas, pelo cònego André Fernandes de Souza. RJHGB, 10(1848)422. ma viagem, o engenheiro encarregado, ao situar um outro dos afluentes do Amazonas, o Rio Madeira, mapeava a produção nativa que poderia se constituir objeto da agricultura, citando os cacoais imensos, as salsaparrilhas, ou pau-cravos, dizendo que muito pouco se conhecia do lugar.

O reconhecimento geográfico visando o enfrentamento à questão do transporte ao interior foi também motivo de muitas viagens. Na mesma época, em 1848 , aparecia uma destas descrições de viagem para reconhecimento fluvial entre as províncias de Goiás e Pará e, nela, o relator, mostrava assombro diante da majestade do rio Araguaia considerando que os seus conhecimentos eram modestos para dar conta de conhecer a região. Esta viagem tinha sido organizada pelo presidente da provincia de Goiás, que pedia descrições do aspecto físico da região para conhecer as condições de navegabilidade daquele rio e outros da região, como o Tocantins. Para o presidente da Província, dizia o relator da viagem, que aquele trabalho significava o

ensnio da navegação do comércio entre esta e a provincia do Grão-Pará pelo rio Araguaia ...

Numa das paragens daquela viagem - Martyrios - o autor, acentuando os aspectos fisicos, descreveu o rio como um corredor entre pedras enormes, dando conta, não somente da geografia fisica do local, mas do uso que os seus habitantes faziam das pedras abundantes, descrevendo, assim, hábitos sociais.

A provincia do Amazonas foi, na metade do século XIX, un alvo constante das comissões de estudos geográficos. Em 1851, o governo imperial enviou outra dessas comissões, esta chefiada por um

8. Viagem de Goyaz ao Pará. Roteiro escrito pelo dr. Rufino Theotonio Segurado. (RIHGB, 10 (1848), p. 178). 
militar do Corpo de Engenheiros do Império, Marcos Pereira de Sales. Ele fez a viagem no vapor Marajó da Companhia de Navegação do Amazonas, recém inaugurada detalhando as condiçōes físicas locais com a finalidade de analisar as possibilidades de povoamento e de desenvolvimento da agricultura local. No seu relatório ao Ministro da Agricultura, Sales enfatizava que, não somente a grande extensão do Pará e Amazonas eram cortados por um maravilhoso tecido de canais navegáveis, mas os terrenos, na quase totalidade os mais férteis e produtivos, eram em quase todos os seus pontos acessíveis por via d'água. Dizia ainda que a enorme lista de produtos silvestres, drogas e especiarias, nada mais exigiam senāo a mão do homem para colhê-la e entregá-la para o comércio, e que a longa série de produçōes agrícolas, com fácil amanho de terras, compensavam largamente o pequeno labor do agricultor".

Confirmava assim a validade da intenção do governo de implementar a conquista do interior a fim de promover o desenvolvimento da agricultura voltada para o comércio, cujo trabalho começava pelas atividades das ciências naturais, no casc, a geografía seguida da geologia, da bolânica e da zoologia. De um modo geral, nesta época, os objetivos que as comissões organizadas pelo governo c/ou financiadas por cste visavam, eram mais ou menos comuns.

A mesma preocupação com o reconhecimento geográfico $\mathrm{e}$ o potencial econômico regional observa-se também nas instruçōes redigidas para a comissão que o governo organizou, $\mathrm{cm} 1851$, com a fina-

9. Eng. M.P. de Sales, Descriçāo e Roteiro de Viagem do Vapor Marajo - desde a capital do Pará até a cidade da Barra da Capinal província da Amazonas. Anexo ao Relatório Anual MACOP, ano 1852, p. 23. lidade de explorar o rio São Francisco, outro local que despertou enorme interesse por ser considerado um corredor entre o norte e o sul. Em 1858, quando foi inaugurado o primeiro trecho de estrada de ferro construído pela Companhia Estrada de Ferro D. Pedro II, o seu presidente, Cristiano Ottoni dizia no discurso inaugural que a região do rio S.Francisco deveria ganhar uma extensão de estrada de ferro pois cste rio era a primeira chave da união nacional (apud KATINSKY, 1994, p.40)

A comissão de 1851 foi presidida por Fernando Halfeld ${ }^{16}$, e tinha por finalidade fazer um minucioso levantamento geográfico da região a fim de criar infra-estrutura para o povoamento". As intruçōes para os trabalhos enviadas pelo ministério do Império, previam o levantamento e planta do curso da estrada e caminhos existentes na direçāo mais reta e conveniente. desde Barbacena até a barra do rio das Velhas na sua confluência com o Säo Francisco

10. O engenheiro Henrique Guilherme Fernando Halfeld veio para o Brasil em 1825, já casado e contratido coıno oftcial inercenário do corpo de tropas estrangciras do Exercito Brasileiro, de que teve baixa em 1830 . Foj entäo trabalhar na $S$. Jolm Del. Rey Minnig Company, companhia inglesa criada para explorar ouro nas Minas Gerais. Trabalhou nesta companhia até 1834. Mas permaneceu em Minas, onde adquiriu terras que continham ininério de ferro. En 18.50 foi designado para explorar o S.Francisco. trabalho que realizou ate $18.54 \mathrm{c} . \mathrm{cm} 18.58$, apresentou ao governo o seu relatório contendo em anexo um at!as do Rio Sāo Francisco (BASTOS, W. de L. Engenheiro Henrique Haljeld. sua vida. sua obra, suu descendência. Juiz de Fora, MG. Ediçōes Paraibuna, 1975. p. (5).

II. Instruções para os trabalhos de Reconhecimento e Exploraçio do rio Sĩo Francisco, em todo o longo do seu curso. Anexo ao Relatório Anual do Ministério do império correspondente a 1851. Ministro: José da Costa Carvalho, visconde de Mont'Alegre. Rio. Typ. Nacional, 1852. 
e. ... desde a barra das Velhas ou Cachoeira denominada Pirapora até a sua embocadura no oceano, devendo designar com minuciosidade a topografia das margens do rio até as extremidades da superficie inundada por suas águas duramte as maiores enchentes, e notar toda a simosidade do seu curso. Deveria também designar todos os obstáculos e embaraços notáveis à navegação do rio, como seja estreitamento do seu leito, cachoeiras, ilhas, bancos de areia, permanentes ou movediços, rochedos vivos, ou pedras soltas, correntezas e hudo enfim que possa de qualquer modo embarafar ou obstar a navegação, devendo ao mesmo passo indicar a confluência de todos os tributários do dito rio; e o curso respectivo de cada um deles até o ponto que a sua navegação for praticável (Anexo ao Relatório anual do Ministério dos Negócios do Império, 1852).

Era, como se vê, um trabalho geográfico bastante detalhado que o governo exigia para a realização do reconhecimento do rio São Francisco. O objelivo da geografia, de realizar a interação do homem com o meio ambiente ficava evidenciado, pois. além da navegabilidade do rio, o governo queria povoar a região para explorar tanto a agricultura como a mineração. Os trabalhos constariam de plantas topográficas c estatísticas dos terrenos dominados pelo rio São Francisco $\mathrm{c}$ scus allucntes desde a barra do rio das Vclhas atć o occano, registrando todas as povoaçōes adjacentes $\mathrm{e}$ informaçōes nccessúrias para o futuro estabelecimento de vias navegáveis, assim, tudo deveria ser comparado com a posiçäo geográfica e fisica desses lugares e com a agricultura, criação e minerafão, salinas, caf̧a, pesca, indístria. manufaturas, comércio atual; indicando-se os resultados prováveis da execuçāo de são vasta empresa. qual há de tornar navegável o mencionado rio em todo o longo do seu curso (idem).

Ou seja, o reconhecimento científico interessava, na medida em que a ciência geográfica apresentava-se como o meio para julgar, se no futuro, aque- la região poderia tornar-se habitada e explorada economicamentc. O trabalho realizado por Halfeld, cujo relatório e atlas dạ região, foram enviados ao gover-

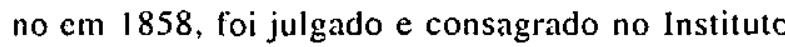
Histórico. Foi considerado como obra de inestimável valor cicntífico e cnviada a diversos países da Europa (BASTOS. 1975, p. 15). Além disso, o Imperador, agraciou Halfeld com o oficialato da Ordem da Rosa. A impressão do trabalho de Halfeld ficou a cargo do Muscu Nacional, cujo diretor, Frederico César Burlamaqui, analisou também uma coleção de amostrals de mincrais colhidas na mesma viagem concluindo que a região, além de ser riquíssima $\mathrm{cm}$ minerais de ferro, continha o calcáreo cujo uso na agricultura $\mathrm{c}$ influência na salubridade pública ninguém ignorava:

Quando os preceitos dus ciências forem mais conhecidos e postos em prática, esses calcareos serviräo para sanear os ponlos deste vasto rio onde atualmente as febres intermitentes amu-

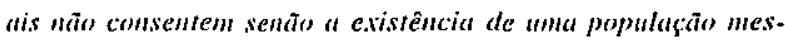
quinha e miserivel ${ }^{1 ?}$.

O diretor do Museu Nacional, ao fazer aquele conentúrio, chamava a atenção para o emprego da cal na agricultura $\mathrm{c}$ na prevenção da insalubridade, um problema que impedia o povoamento mais sistemático de uma regiño tão rica. Eram, certamente, as questóes que o governo queria ver apontadas pelos trabathos para facilitar a agricultura nas diferentes regiōes do país. O relatório do Ministério do Império relati-

12 BURLAMAQU1, F.C. Oficio ao Ministro do Império de 20 de agowo de 1858 (Arquivo Administrativo Histórico Científico do MN - AAHC-MN -, doc.25, pasta 6). Em 186I a obra de Halfeld foi incorporada à biblioteca do Museu Nacional (AAHCMN, doc. 130 , pasta 6 ). 
vo ao ano de 1855 contém um outro relatório sobre um outro local da mesma regiño: o rio das Velhas.

A viagem ao rio das Velhas tinha sido uma iniciativa do entāo presidente da província Francisco Diogo Pereira de Vasconcellos e foi dirigida pelo engenheiro civil E. de la Martinière ${ }^{13}$. Do relatório do engenheiro Martinière constam os orçamentos $\mathrm{c}$ cálculos dos projetos de construção de estradas c estudo sobre a navegabilidade do rio cuja execuçāo era importante porque:

seria ofim do estado de isolamento dayueles lugares - estariam ligados o Sul e o Norte do Império e abriria uma communicuça interion: permitindo a explor'ugän das riguezas que af se encomtram. (grifos meus)

A valorização do interior do país estava alí resumida, mostrando que havia uma política consciente em favor de fazer a unidade do império brasileiro, ligando o sul $\mathrm{c}$ o norte. A interiorização tinha sentido porque era nas terras ainda virgens que sc encontravam as grandes riquezas a explorar. Como dizia o mesmo engenheiro Martinière no scu relatório:

é pois do interior do Império que o governo tirari suas maiores riquezas e sua maior forsa. quando as cossas näo possam senāo servir de pomos de possagem aos produms indigenas e exi-

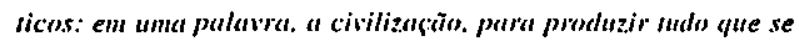
tem direito de esperar e de exigir delo. deve ier suas bases estabelecidas ao abrigo das eventualidades e das grandes guerras. e possuir no imerior os meios de ascăo gue assegurem "futuro a prosperidasle da popular'iono.

Aquele rclatório deixava bastante claros os objetivos políticos de, fazer do cultivo dos produtos que

13. L. P. do C. FERRAZ (ministro), Relatiorio Amual do Ministério do Império/l855. Rio, Typ. Nacional, 1856, Anexo: $O$ rio das Velhas. Sobre o engenheiro não obtive mais informaçōes que as do Relatorio. o interior do país poderia produzir um meio de realização da unidade do império, mantendo interior e centro político unidos pelas vias de comunicação comerciais. A polftica de construção da naçāo visava o desenvolvimento das ciências que propiciavam o conhecimento das riquezas e o povoamento para, em última instância desenvolver a agricultura. Esta era, pode-se dizer, o escopo material da idcologia da unidade nacional ${ }^{14}$.

As comissões de levantamento e estudos daquelas regiões de passagem entre o sul e o norte foram reincidentes. Na década seguinte àquelas viagens, foram enviadas à regiāo do São Francisco, pelo menos mais duas comissões que tornaram-se bastante conhecidas. Uma delas foi a controvertida comisst̃o dirigida pelo francês Emmanuel Liais, e a outra foi a conhecida comissão Agassiz. Sobre a primeira, que teve como auxiliares os brasileiros Ladislau Neto c Eduardo José de Moraes, comentou José Veríssimo da Costa Pereira que, sob o ponto de vista cartográfico e gcológico, foi inferior a de Halfeld e solireu severas restrições no Brasil's. Na verdade,

14. Analisando o momento de passagem da colonia para o império. Ma. Odila da S. Dias concluiu que havia desde a vinda da corte para o Brasil uma intençỉo política de integrar o território pelo comércio dos produtos nativos do pals. Este processo político. que cla chamou de a interiorizas'aün da metripole corroborou a conlinuidade da ıradiçâo portuguesa no país c a inıegração do território pela exploração dos recursos naturais delineando a iınagem do governo central forte $\mathrm{e}$ a neutralizaçĩo dos conflitos regionais (DIAS. 1972, p.160-184).

15. PEREIRA. J.V. da C. "A Gcografia no Brasil" in. AZEVEDO. F. de. As Ciências no Brasil. Säo Paulo. Melhoramentos. 1955. p.352. v.l. O tivro de Liais: Climats, Geologie, Faune et Gèngraphic Bonanique du Brésil foi publicado na França em 1872. Eim 1870, cle foi nomeado diretor do Observatório Nacional. então desmembrado da Escola Central (MORAES, A. A Astrono. min m Brasil, in AZEVEDO. p.128). 
os brasileiros que acompanharam Liais tiveram com ele sérias divergências, principalmente Lasdislau Nețo que não se conformou em ceder o herbário que criara por ocasião da viagem ao São Francisco, e escreveu ao Imperador criticando a maneira pouco profissional como tinha sido tratado durante os trabalhos da Comissão e depois em Paris, onde o trabalho deveria ser redigido ${ }^{16}$. Certamente, com isto, muitos dos trabalhos da comissão se perderam.

Ladislau Netto ofereceu ao Imperador a coleção de plantas que havia classificado na viagem, destacando a importância das classificações da flora indígena, cuja prática reputava importante, uma vez que também era uma justificativa para a abertura de tantos caminhos para o interior, como o eram os estudos zoológicos e mineralógicos. Sobre estes últimos, as pesquisas em geologia dividiam-se entre o conhecimento das rochas (fósseis) e em função de tornar conhecidas as propricdades do solo (FIGUEIROA, 1992).

A mesma justificativa de abrir caminhos para a exploração das riquezas foi utilizada pelo governo quando da vinda para o Brasil da conhecida Comissão Agassiz. Nesta ocasiāo, o governo imperial julgou honrar-se proparcionando-lhe todas as facilidades a seu alcance para o bon êxito desta exploraçào científica, cujos resultados, interessando a todos, com mais particularidade aproveitam ao im.

16. Neto L. - Carta ao Imperador de 28/09/1866 (Arquivo do Museu Imperial de Petrópolis - M 138/D 6781). Certamente, Liais tambêm divergia de Ladisłau Neto, pois em julho de 1866, escreveu ao limperador criticando as suas atitudes posteriorntente à volta đa comissāo (Arquivo lınperil de Peirópolis, D6781 MI38). Porém, nenhum dos dois teve problemas com o Imperador. Liais voltou ao Brasil e foi diretor do Observatorio Nacional nos anos 70. Neto, que era, na ocasiāo, diretor da seçăo de Botânica e de Agricultura do Museu Nacional, em 1876 foi nomeado diretor geral da instituiçāo. pério que ainda não possui um inventário completo de suas inumeráveis riquezas, e dos diferentes elementos da sua prosperidade, que com tão libér. rima mão o dotou a Providência (Relatório anual do MACOP, 1866, p. 27).

$O$ governo queria que o inventário das riquezas nacionais fosse feito por brasileiros e, que

Melhor oportunidade se nãs podendo por cero encontrar: para proporcionar à mossa mocidade estudiosa e dotada de täo brilhantes talentos e inserpretacioes. o esfudo do grande livro da natureza sob a direçäo e liçoes de täo instruido professor. intentei criar uma comissän anexa à americana... (Jdem, grifo meu)

O ministro então justificava que enviara apenas um professor competente porque não tinha meios para financiar uma Comissão. Enviava então o professor engenheiro João da Silva Coutinho que julgava possuir os conhecimentos científicos necessários da geografia do local bem como dos hábjtos indj́genas. Os conhecimentos geográficos foram determinantes para o engajamento de Silva Coutinho na Comissão Agassiz. E, embora a Comissão de Agassiz tivesse interesse particular na ictiologia, o comissário do governo respondeu à missāo apresentando uma geografia botânica da região, em que fazia um relatório das propriedades tanto terapêuticas como industriais e vantagens da cultura de frutos e flores, assinalando por exemplo as propriedades ainda desconhecidas do Uaraná, considerado um produto precioso, c cujo uso poderia estender-se desde que fossem conhecidas e estudadas suas propriedades (idem, p.28). Fazia também apreciaçōes sobre o regime das águas, o curso dos rios, suas anastomoses e entrelaçamentos. Para o ministro, as considerações de Silva Coutinho tinham nāo só contribuído para habilitar melhor os navegantes, como tinham enriquecido os seus conhecimentos, bem como fornecido dados mais seguros sobre as condições topográficas e zoológicas quc explicavam as singularidades da região 
e abriam caminho para novos estudos e para apresentação de soluçōes administrativas, principalmente sobre a salubridade do clima e moléstias locais (idem, p.29). Vê-se claramente que os interesses do governo estavam por trás dos trabalhos de levantamentos científicos sobre a região do Amazonas porque, como era acrescentado no mesmo relatório:

A regiao amazónica é un novo mundo, que pode conter, alimentar, e desenwolver uma populas:an maior de 20.000.000: " inaproveitamen!s de seus produsos naturais, na opiniāo das mais respeifaveis autoridades, pode ser avaliado em cerca de 50.000.0005000. Poderínmos ter neste pressuposto cinquema milionários anualmente, se nos déssemos ao trabalho de ir ajuntar o que a natureza nos oferece com mato täo prodiga.

Era ao povoamento da regiảo amazônica que o ministro se referia mostrando que, em última instância, as riquezas naturais infindáveis daquela riquíssima regiāo reclamavam o trabalho do homem, ou seja, reclamavam a agricultura. A relação homem/ natureza mais uma vez ficava evidenciada como a base da construção da nação $\mathrm{e}$ foi reafirmada pelo proprio Agassiz, na sua Journey in Brazil. Elc dizia que no Brasil havia coisas entristecedoras, mas que havia outras a louvar que dava a conviç̧ão de que esse jovem império se erguerá como nação, à altura da magnificência que possui como território "'.

A busca da integração do território pela exploração da riqueza e pelo necessário povoamento, apresentava-se, igualmentc para políticos $\mathrm{c}$ intelectuais, como uma condiçāo da transformação do império em nação. Isto explicava as rciteradas viagens às regiōes,

17. AGASSIZ, L. Journey in Brazil. Cambridge University Press, edição de 1909. I" edição 1867. p.196. Viagem ao Brasil. Rio, Companhia Editora Nacional, 1938, p. 589. O autor assinalava que haviam dois graves obstículos ao progresso no Brasil: a escravidåo e o clero. às regiões diga-se de passagem, consideradas mais ricas e menos povoadas, como o norte amazónico. O ministério da Agricultura, Comércio e Obras Públicas, incentivou, por exemplo, a publicação do díário de viagem de Agassiz porque considerava que 0 seu trabalho resultaria no grande livro da natureza brasileira, que seria uma verdadeira revelação para a ciência e, tornaria mais conthecidas a fertilidade e riquezas naturais do vale do Amazonas. Para o ministro, a abertura do rio Amazonas e de alguns dos seus afluentes à navegaçāo de rodas as bandeiras, vão atrair por certo todas as vistas da ciência e servir de teatro à grandes especulą̧ões comerciais ${ }^{1 \mathrm{x}}$.

Da Comissĩo Agassiz derivou, mais tarde, a conhecida Comissão Geológica do Império do Brasil que, sob a direção do geólogo que acompanhara Agassiz, Charles Hartt, propôs-se fazer um amplo levantamento da geologia do país que estimularia a mineração e a agricultura, e ela obteve inteiro apoio do governo imperial (FIGUEIROA, s/d, p.l2). $O$ plano de Hartt previa, entre outras coisas.

"estud" da estrubura geoligica do lmperio, ... das riquezas maleriais. ... do valor ecomimico destes materiais e da facilidade de obtê-los para a mineraçäo e mantfatura (fdem).

O apoio do governo a tais comissōes evidenciou a fortc valorização das ciências naturais naquela época. A preocupação com as comunicaçôes, os transportes $\mathrm{e}$ o assentamento regional de pessoas interessa. das no cultivo daquelas regiōes ainda nāo conhecidas cra, ao mesmo tempo, objeto político c justifi.

18. Relatório do MACOP de 1866. Rio. Typ.Nacional. 1867. p.49. Naquele relatório dizia-se que o governo brasileiro havia enviado aos Estados Unidos o professor de hipiátrica da Escola Central. Félix Vogelli, para traduzir o trabalho de Agassiz para o francês, a fím de publich́-lo na França e na Bélgica (onde o governo autorizou a publicação mos nāo iria financiá-la). 
cativa aos estudos científicos que versassem tanto sobre a geografia, como a geologia, a etnografia, ou a astronomia. Esta última, incluída na seção de geografia da Comissão Científica de 1859, instruía que compreenderá observações astronômicas e operações topográficas concernentes à determinação da posição geográfica dos pontos mais importantes do territorio explorado...e, trabalhos de mera investigação, que interessam imediatamente a fisica geral do globo e os que tiverem por objeto a sugestäo de importantes melhoramentos materiais, de que careçam as provincias visitadas pela comissão exploradora, uma vez que tenham eles alguma conexâo com a natureza dos trabalhos incumbidos à referida seção (Trabalhos da Comissão Científica, op. cit.).

Os melhoramentos materiais estavam subordinados aos objetivos científicos na referida Comissão, mas nem por isso deixavam de constituir o seu pano de fundo. Nesta seçāo, chamada de Astronomia e Geografia realizar-se-iam trabalhos para observações meteorológicas, pressões barométricas comparadas à determinação de latitudes e altura meridiana, com uso de cronômetros, distâncias lunares etc.,

dando preferência aos hugares situados nas mangens doss rios. ao volume das suas aguas e à velocidade das suas corremes: às condiçies de navegabilidade on ao regime do seu curso (ldem. Grifo meu).

Ainda deveriam especificar as condições atmosféricas locais, as variações da agulha magnética c, uma vez estando no Ceará, região que sofre o flagelo da seca, a seção astronômica de acordo com a seçāo geológica. [faria]... precisos exames de sondagem, a fim de descobrir os indícios que possam servir de guia para tentar-se oportunamente a abermra de um poço artesiano, o qual (no caso de surtir efeito) possa ser considerado como norma para a abertura de outros poços, de que carecem diversas localidades da província. Todo o amplo trabalho conduziria a um estudo acurado sobre a conveniência e praticabilidade da abertura de comunica̧̧ões fáceis entre os centros de produção do interior da província do Ceará e os seus portos e, sobre melhoramentos de que carecem estes portos para que sejam acessiveis às embarcaçōes que fazem comércio direto com o exterior (Idem).

Propunham portanto que a Comissão Científica nāo trabalhasse apenas em prol das ciências, mas que, os seus trabalhos tivessem como conseqüência a criação de uma infra-estrutura na província para facilitar a exploração e o comércio dos produtos nativos. Especificamente em relação à agricultura, era a seção de geologia que deveria proceder a uma coleçāo dos diferentes solos em quantidade suficiente para que se possa determinar o seu grau higroscópico, de aquecimento e conservação das temiperaturas, assin como as diferentes análises químicas. As amostras deverão trazer as seguintes indicaçōes: se mato virgem, capoeira, alagadiço etc .... ou campo cultivado, e neste caso qual a planta que produz melhor nele, se se acha esgotado para uma ou mais plantas, com quantas culturas se esgota, e que tem. po leva para regenerar-se. Acompanharão as ditas amostras uma porçāo de tronco, folhas e frutos dos vegetais que eles de preferência produzem ... (Idem: Instruçōes para a Comissão de Geologia).

Com esta mesma finalidade, de fazer um levantamento para promover a exploração de produtos nativos, o Muscu Nacional incentivou também as viagens e deu grande apoio à figura do viajante-naturalista. Ainda em 1843, a dircçāo do Museu recebeu uma carta do naturalista Claussen revelando as riquezas da regiāo do rio Sāo Francisco, principalmente no tocante à descoberta de minas de metais ${ }^{\prime \prime}$.

19. Aviso de 8 de novembro de 1843. AAHC-MN - doc.168. pasta 2. 
A preocupação em formar coleçðes para o Museu com os produtos das mais diversas regiōes do Brasil que havia começado desde a independência determinou, naquela ocasião, o aproveitamento dos trabalhos nas províncias como o do cirurgiāo-mor da Armada, Henrique Raymundo de Genettes, na região do vale do Rio Grande em Minas Gerais, e cujo relatório dava informações detalhadas sobre os aspectos físicos da regiāo, os seus minerais etc. ${ }^{211}$. Bem como, o Museu, determinou a contratação de viajantes como João Theodoro Descourtilz, recomendado para visitar, em 1847, a província do Espírito San$10^{21}$, ou a de Alfredo Soyer de Gand, que foi encarregado do Museu para colher material para o mesmo, nas províncias do Pará e Amazonas, em $1855^{22}$.

Decididamente, nas décadas que mediaram o século XIX, a preocupação em conhecer o interior do Brasil, seu aspecto físico e suas potencialidades. estimularam tanto as pesquisas científicas como estruturaram a política de construção da nação, deixando, porém, a dúvida sobre qual seria a causa ou qual seria a consequiência. Certamente, se não houvessem estudos anteriores, a política nāo poderia valer-se de teorias científicas para tomer determinadas iniciativas. É preciso lembrar por outro lado que data daquela mesma época a publicação dos relatórios de muitos naturalistas curopeus que haviam visitado o Brasil, e cstes eram divulgados principalmente pelo IHGB.

20. Relatório enviado em 27 de agosto de 1845. AAHC-MN - doc.20. pasta 3.

21. Aviso de 20 de outubro de 1847. AAHC-MN - doc. 92 , pasta 3.

22. Oficio de 14 de julho de 1855. AAHC-MN - doc. 27. pasia 5.

\section{A Etnografia e o Povoamento}

Tanto as viagens como as publicaçōes sobre elas que se sucederam naqueles anos do meio do século XIX, principalmente no Instituto Histórico, apresentavam a dupla finalidade, da busca de conhecimento dos aspectos físicos e de contato com a vida dos índios. Os índios, ou os selvagens, como eram tratados na literatura especializada, representavam o oposto à civilização. Porém, ao mesmo tempo eles cram representados como símbolos da liberdade, e como os substitutos dos escravos. Neste sentido, a etnografia, que naquela época era vista como o estudo da maneira pela qual as sociedades se formaram, estabeleceram, regularam ou se elevaram pouco a pouco e sucessivamente aos diversos graus de civilização (DUCHET, 1985, p. 20), faria a ligaçāo do contexto social brasileiro à ideologia de construção nacional. Esta preocupação de tirar os índios do seu estado selvagem manisfestava-se nos objetivos do Instituto Histórico e Geográfico Brasileiro, e também, nos atos políticos do governo de promoção às viagens dos naturalistas ao interior do país.

A etnografía não teria unicamente a finalidade de percorrer os caminhos que levassem à taba selvagem cm busca do elo que a ligasse ao passado brilhante livre dos grilhõcs coloniais, como disse certa ocasiño o Secretário do IHGB (apud DOMINGUES, 1990, p.80). A rejeiçāo ao período colonial, cujas críticas apareccram mitigadas a muitos trabalhos daquela instituição, davam o timbre aos trabalhos que se pode classificar como etnográficos, entretanto, ao mesmo tempo eles levantavam problemáticas de posse do interior do Estado imperial, do seu povoamento, de conservação de fronteiras c garantia de māo-de-obra para a agricultura (idem, p.90).

$O$ adiantamento dos índios, tornando-os aptos para o trabalho agrícola, segundo Cunha Barbosa, secretário do Instituto Histórico e Geográfico, viria com a ação de civilizá-los, o que, para ele, requeria 
o conhecimento dos seus usos e costumes, isto ć, da etnografia. Neste caso, pode-sc perguntar se a necessidade de mão-de-obra para substituir os escravos negros levaram ao estudo da vida indígena dando início à etnografía no Brasil? Na verdade, ć inegável a enorme incidência de trabalhos discutindo o modo de vida dos índios, suas aptidōes, sua organização social etc., que apareciam na revista do Instituto Histórico e Geográfico Brasileiro naqueles anos.

Por outro lado, as Instruçōes para a organização da Comissão Científica de 1859, mostravam uma faceta mais ampla dos propôsitos da prática da etnografia num Brasil constituído sob o plural de raças. Para a Comissão Científica, a Etnografia, apresentava o objetivo do estudo da vida indígena a fim de determinar os elementos que a distinguiam como raça humana, observando: sua organização, o seu caráter intelectual e moral, as suas linguas e as tradições históricas, para assentar em suas verdadeiras bases a ciência da etmologia (Trabalhos da Comissão Cientifica; op,cit., Instruçōes). Mas nāo era apenas à distinção biológica de raça humana que se referiam aquelas Instruçōes quando diziam que a etnografia buscava distinguir tanto aspectos físicos do homem, como aspectos sociais. Os organizadores da Comissão Científica objetivavam aqueles estudos porque

o homem genuinamente americanopode ser chamado a compartilhar da civilizaçõo. e volumarimuente prestar-se à comunhäo brasileira, se empregarmos os meios comsefineos am a

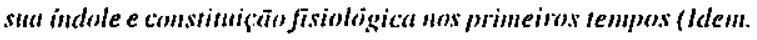
Crifas meuss).

Certamentc que os índios prestar-sc-iam à comunhăo brasileira na medida $\mathrm{cm}$ que se transformassem $\mathrm{cm}$ partícipes do sistema produtivo edificador da naçĩo. Os índios podiam ser chamados se fossem convenientemente tratados, ou seja, se livres, fossem subordinados ao poder civilizado, o que não acontecia em relação aos negros, considerados estrangeiros. Ao mesmo tempo, o conhecimento do modo de vida dos índios podia render vantagens adicionais, tais como, conhecer a extensão da sua agricultura, o modo porque a fazem, e as plantas mais usuais da sua nutrição, as farinhas e as bebidas que delas tiram. a qualidade destas bebidas, segundo as estafóes e as festas em que são usadas, os meios que empregam na criação dos quadrípedes e aves, que os seguem por toda parte ... (ldem)

Mostravam que estavam cientes da importância de cstabelecer um canal de troca de conhecimentos com os índios, de quem muito poderiam aprender sobre os segredos da natureza local. Nesta troca de conhecimentos o resultado poderia ser a ciência mestiça, no sentido que deu ao termo Michel Paty, pois este autor observou que o dicionário científico de plantas, animais, ou lugares, formou-se com grande número de palavras oriundas da língua Tupi e, tais palavras, retiveram no seu sentido os dados de conhecimento sobre as propriedades dos elementos da natureza, tal como os índios as compreendiam (PATY, 1990, p.82). Ao mesmo tempo, uma ciência para a agricultura, fundada nas experiências e tradições de cultivo criadas pelos índios, contribuía para dar originalidade à agricultura do país, tanto do ponto de vista das espécics cultivadas como dos terrenos e dos métodos de plantio. Os conhecimentos adquiridos analisando as práticas tradicionais locais podiam, quem sabe, vir a criar bases para uma ciência nacional.

É certo contudo que, além da promoção de viagens ao interior do país, o Instituto Histórico e Geogrífico Brasilciro, promoveu correspondência com os presidentes provinciais, a fim de conhecer a potencialidade cultural daqueles índios, que eles, inegavelmente, viam como mão-de-obra possível do país ${ }^{2,3}$.

23. BARBOSA, J. da C. Se a Introdução dos escravos africanos no Brasil embaraça a civilizaçăo dos nossso indígenas, dispensando-Jhes o trabalho, que todo foi confiado a escravos ne- 
Desde os seus primeiros números a Revista do IHGB publicou trabalhos exaltando a vida indígena e os primeiros contatos que os europeus tiveram com eles, mesmo quando estes nảo haviam logrado êxito, como no caso dos exertos da obra do padre João Daniel sobre o Amazonas, escritos no século XVI e, em cuja Segunda parte do Tesouro descoberto do Rio Amazonas começava dando notícia geral dos Indios seus naturais, de algumas ną̧ões particulares, da sua fé, vida, costumes e das causas mais horáveis da sua rusticidade, desenhando uma imagem de selvageria indomável (Revista do IHGB, 2 (1840), p.329). A publicação de tantos artigos abordando o cstabelecimento de contato com os índios e a exploração do interior tinha, no entanto, uma finalidade semeIhante à do padre LuizAntonio da Silva e Souza, apresentada naMemória sobre o Descobrimento, Governo, Populą̧ão e cousas mais notáveis da capitania de Goiás, escrita em 1812, onde se pode ler que a redução dos índios à chamada sociedade civil teria como conseqüência o povoamento das margens dos rios navegáveis e que, girando por todas as partes as embarcações com as produçōes do país, e ao mesmo tempo empregadas as águas em mover pesadas máquinas, que poupam os trabalhos dos homens; vejo adiantadas as artes e as ciências, promovida a indistria animando o comércio, penetrados os seriōes e descobertas as suas preciosidades; vejo marchar de um passo igual a agricultura e a mineraçāo; cobertas de rebanhos as campinas; coroados de vinhas os outeiros; crescerem as povoaçōes e fundarem-se cidades (Revista do IHGB, 12 (/850), p. 429-5/0).

gros. Neste caso qual é o prejuizo que sofre a lavoura brasileira? RIHGB, 1(1839)145; ... Colonizar os índios entranhados em nos. sos sertōes: fundado, principalınente, na propagação do cristianismo, ou se outro do qual se esperam inelhores resultados que os atuais. RIHGB, 2(1840) 3.
Era assim também, com tal visão de utilização dos índios como povoadores e cultivadores que o governo projetava o desenvolvimento do interior do país, visto como um meio de implementar a unidade do império. O conhecimento dos índios e do interior era incentivado pelo Imperador que oferecia prêmios, ou encomendava trabalhos que melhor respondessem, por exemplo, sobre quem eram os povos e que melhores possibilidades ofereciam à empresa da civilização 24 .

As inúmeras publicaçōes de relatos de viagens nas páginas da revista do Instituto Histórico, retratavam os objetivos de reconhecimento geográlico e etnográfico do país desde o Amazonas, até a região sul onde anteriormente os missionários haviam dominado os índios e obtido razoável desenvolvimento agrícola"s. Nas descriçōes de viagens procuravam apresentar, além das condições de penetração no inóspido interior, a vida dos índios que encontravam ao longo dos caminhos, sua comunicabilidade e suas habilidades artesanais. $O$ conhecimento das possibilidades de contato e convívio com os índios era importante porque eles não cram os únicos grupos sociais previstos para habitar o interior. Nesta mes-

24. De uma destas cncomendas, feita a Gonçalves Dias, resultou o livro Brasil e Occania. que o IHGB publicou na sua revista em 1867. O autor comparava os orientais aos indios concluindo que estes lt ímos, Jespojados de tradição, eram ınais afejtos ao trabalho porque seriam mais facilmente catequizados (RIHGB, 35 (1867), p. 5).

25. Memória sobre a Província das Missōes. Oferecida ao Conde de Linhares, Ministro e Secretário do Estado dos Negócios Esırangeiros e da Guerra por Thomaz Ja Costa Correa Rabello e Silva (RIHGB. 2 (1840), p.155); Viagenn de Cuiab́́ ao Rio de Janeiro, Corrientes, Rio Grande do Sul, e Santa Catarina, em 1846, por Henrique Beaurepaire Rohan, Major do Imperial corpo de Engenheiros. (RIHGB, 9 (1847), p.376). 
ma época estava em curso o movimento $\mathrm{cm}$ prol da imigração dos curopeus para o Brasil.

Em 1851, quando o governo imperial enviou ao Amazonas a Comissão de Navegaçāo do Vapor Marajo chefiada por Sales, este salientava que

... todas estas madeiras e drogas, todos estes produtos sitvestres e agricolas que existem no seu exfado natural on em caltura nascente sem esperanca de progresso pela falia quase absoluta de quem trabalhe. um grito se desprende quase involumtariamente dos labios do observador: Bragos! ... (op. cit. Relatorio do Ministério do Imperio. 1852, p.23).

As viagens, realizaram-se naqueles anos de meados do século XIX com a preocupação de estabelecer no interior do Brasil colônias de povoamento. Algumas delas tinham o objetivo de estudar as condiçōes de estabelecimento dos imigrantes europeus cuja propaganda na Europa das riquezas que o país oferecia era enorme naqueles anos. Os relatos destas viagens falam não somente da geografia local mas sublinham o contato que empreendiam com os índios, dos seus hábitos guerreiros de atacar os estranhos ou, ao contrário, dos scus modos tímidos, que os mantinham longe dos povoadores estrangeiros. Em 1858, Avé-Lallement viajou com o objetivo de informar os seus patrícios alemāes sobre o interior do país, andando principalmente pelo sul, fe $\%$ um paralelo entre as boas condições ambientais e a passividade dos índios. A região, para ele, tinha todas as boas condições para a agricultura, pois, além de fornceer bons alimentos como, arroz, feijão, farinha de mandioca, batata, ou cereias, tinha água potável c os bugres que cram passivos, não apresentando cmbaraço à imigração (AVÉ-LALLEMENT, 1980, p. 98).

Uma outra viagem realizada no interior da regiāo leste, saindo da Bahia para o sul, $\mathrm{cm}$ meados da década de 1840, valorizava juntamente com a geografia c a preocupação em desenhar os contor- nos físicos dos lugares, uma forte preocupação com a língua indígena ${ }^{36}$. Marcando as longitudes e latitudes dos lugares, sob orientação de uma bússola, o autor não somente ia descrevendo as paragens como ia enumerando as riquezas naturais, por exemplo, em madeiras, que se apresentavam com tamanha abundância em alguns lugares, como o conhecido como Serraria dos Padres, lugar que exigia o conhecimento da língua indígena para atingi-lo. Daf ele incluir no seu trabalho um vocabulario desta língua. Também como parte da etnografia, o conhecimento lingüístico apresentava-se, segundo este autor, imprescindível nas viagens. Ele mostrava ainda como viviam os indígenas ao longo do caminho percorrido, dando conta de especifidades da sua vida (Idem).

Tratando também da língua indígena, a revista do Instituto Histórico e Geográfico publicou, em 1848, o artigo Novos indicios da Existência de uma Antiga Povoação Abandonada no Interior da Província da Bahia ${ }^{27}$. A comunicação com os índios cra conveniente pois, além de facilitar o contato, contribuía para aprender muitos dos segredos que a natureza local guardava. A maneira de abordar o tema

26. Viageın à vilas de Viçosa. Porto Alegre, de Mucury e oos rios Mucury e Peruhipe: relatório de Hermenegildo Antonio Barbosa d'Almeida, escrito na Bahia em setcmbro de 1845 (RIHCB. 8 (1846), p. 425).

27. Enviada ao Instituto pele Major Manoel Rodrigues de Oliveira ( $R I H G B, 10$ (1848), p. 363). Abordando o tems dos indios apareceram publica, a agricultura de exportação do Brasil que. nas primeiras décadas do século XIX. em alguns momentos sobrepujou as economias concorrentes como, por exemplo a dos Estados Unidos da América do Norte, aos poucos foi perdendo o terreno e, enquanto o voluıne deste último se multiplicava, o volume das exportaçōes brasileiras para a Europa que era o seu gronde comprador. apenas somava algumas libras. 
lingứstico associava-o ainda à questão da mão-deobra como era lembrado num artigo $\mathrm{cm}$ que o autor frisava a necessidade de tirar os índios dos seus costumes para transformá-los em mão-de-obra, isto é, estabelecer os seus interesses na civilização, com arte, zelo e conhecimento local; com paciência e autoridade (Revista do IHGB, 8 (1846), p.494).

$O$ plantio, que por sua vez exigia povoamento. viria a ser uma outra mola propulssora dos estudos etnográficos mostrando, mais uma vez, o casamento das ciências com a política de construçāo da nação. O contato com os índios cra importante na visão de sócios do Instituto Histórico porque nas atuais circunstâncias do Brasil e da política européia. a civilização dos índios bravos (...). com novas aldeias, que se forem formando, a agricultura dos gêneros comestiveis e a criação dos gados devem aumentar, e pelo menos equilibrar nas províncias a cultura e fabrico do af́icar (Revista do IHGB, 12 (1850), p.143).

Por outro lado, para os construtores da história do Império, reunidos no IHGB, a questano dos índios sempre esteve em primeiro plano uma vez que thes importava o fato de terem sido os prime:ros habitantes do Brasil. Porém, não se pode negligenciar a pressão que os ingleses exerceram para acabar com o tráfico escravo. A cessação do tráfico que ocorreu finalmente em 1850, acelerou a valorização dos ín. dios que, a meu ver, passaram a ser vistos mais sistematicamente como potencial de mão-dc-obra para a lavoura e daí derivaram muitos daqueles cstudos sobre a sua vida e a sua cultura, dando enorme valorização a etnografía (DOMINGUES, op.cit.). Do lado da política, data de 1845 a reedição da criação da Diretoria dos Indios, em que o governo propunha o seu aldeamento sob as ordens de um administrador nomeado (Decreto $n^{4} 426$ de 24 de jutho de 1845). E, em 1847, a estrutura organizacional do próprio Instituto Histórico foi alterada em função da introdução da nova Comissāo de Emo- grafia e Arqueologia Indigena ${ }^{2 h}$, que passou a atuar logo em seguida, embora tivesse sido incluída nos estatutos da instituição somente em 1851, quando estes foram alterados.

Nesta época, os intelectuais não escondiam a inviabilidade econômica e moral da escravidāo negra e enfatizavam a necessidade de uma agricultura baseada na mão-de-obra livre. Lembrando os princípios econômicos do capitalismo, cra sublinhado pelo secretário do Instituto Histórico que o fim da cscravidāo era, em todos os sentidos, um bem não somente para os proprietários, como também para as terras e suas preciosas culturas:

Nossas manas preciosas em madeirar de consmuģän cinil e náutica não seriam destruidas pelo machado assassino do negro, e pelas chamas dev'astadoras da ignorância. Os cumes das nossas terras baikas, e de cinculagăo elérica, näo estariam esscavados e tostados pelos ardentes estios dos nossos climas. $\dot{E}$ pois evidente que se a agricullura se fizer com bragos lives dos pequenos proprietarios on por jornaleiros, por necessidade e interesses serāo aproveitadas essas terras, mormente nas vizinhanpas das grandes povorscios. onde se acha sempre um mercado, cero, pronto e proneitoss; e deste modo se conservaräo. como heramga sagrada para a mossa posteridade. as antigas matas vir. gens. que pela sua vastidho e frondosidade caracterizam onosso belo pais (Idem. noia 24).

Política c cconomia justificavam a extinção da escravidão, ou do tráfico c, sugeriam a aproximaçāo aos índios, fosse para aprender a conviver com a pre-

28. Ata da Sessāo n² 177: Revisı do IHGB, 9 (1847), p. 439. A arqueologia interessava dirctamente aos historiadores que deviam estabelecer a origem do país e, por outro lado, fazia desenvolver estudos de fósseis que acabaram por relacioná-la com a geologia. Tais especifidades das ciências naturais fogem, infelizmente, aos limites deste trabatho. 
sença deles, fosse para transformá-los em mão-deobra livre substituindo a escravidão. Os estudos publicados sobre a cultura indígena discutiam a sua maior ou menor organização social, isto é, seus hábitos domésticos alimentares, sua medicina, suas hierarquias e atribuiçōes no interior do grupo, discutiam o papel da mulher no mesmo, os hábitos sexuais, a arquitetura das habitações etc. Tais trabalhos tinham o cuidado de mostrar que haviam diferenças tribais, sendo alguns grupos mais bravos $\mathrm{e}$ arredios que outros e, apontavam sugestōes para a melhor aproximação de cada um aos cômodos da civilização (ELLIOT, Revista do IHGB, 10 (1848), p.153).

A diferença entre o bom e mau selvagem foi lembrada em diversos relatórios e artigos publicados na Revista do IHGB. No relatório de uma viagem realizada para estudar a navegabilidade no rio Paraguai, ao sul do Mato Grosso, era assinalado, pelo relator, o major do corpo imperial de engenheiros, Henrique Beaurepaire Rohan, que havia diferenças de indole entre os índios: ou cra boa ou era má, mas eles mantinham sua independência que muitas vezes se mostrava à civilização pelo lado que menos lisonjeia o homem (Revista do IHGB, 9 (1847), p. 276).

A boa ou má índole que se imputava aos índios, faz lembrar premissas da conhecida filosofia das luzes que levantou o debate rousseauista sobre o bom ou o mau selvagem. No Brasil, os considerados filósofos iluministas não eram desconhecidos, Rousseau chegara a criar partidarismos ${ }^{29}$, deixando ainda mais

29. Varnhagen ao publicar a sua História Geral do Brasil, concordando com von Martius, o naturalista alemão, dizia na introduçīo da sua História Geral que não tinha sentido uın historiador nacional ostentar o pseudo-filosofismo rousseauista no entusiasmo filo-selvagem (Histoiria Geral do Brasil. $1^{2}$ edição. Rio, Editora Laemmen. 1854, p.XXVIIJ). Entretanto, alguns anos an- clara a relação do discurso político-ideológico de construção da nação aos valores da chamada filosofia das luzes. A relação homem/natureza era não somente o escopo da ideologia de construção da nação, mas representava a manutenção da agricultura como a base econômica do país, demonstrando o alento e a legitimidade que receberam as ciências envolvidas naquela relação.

A etnografia, foi institucionalizada no Brasil, pode-se dizer, em duas etapas: timidamente, em 1842 quando foi reformada a estrutura do Museu Nacional e criada a Sessāo de Numismática, Artes Liberais, Arqueologia, Usos e Costumes das Naf̧öes Modernas e, em 1847, quando foi criada a Comissão de Arqueologia e Etnografia Indígena no Instituto Histórico, acima referida. No Museu Nacional, os relatórios daquele período apontam poucos trabalhos da Sessāo correspondente à etnografia, mas aos poucos a sessão foi angariando maior atenção e na década de 1870 , o diretor do Museu, Ladislau Netto, ao falar dos salões de exposição do mesmo Muscu dizia sobre o salão $\mathrm{n}^{2}$ 9, de Arqueologia. Numismática, e Antropologia que era o mais importante que oferecia o Museu Nacional, pois este possui a mais completa coleção etnográfica que jamais se viu de nossas numerosas tribos indigenas (NETO, 1870, p.286).

A etnografia, na reforma organizacional do $\mathrm{Mu}$ seu, ocorrida em 1876, foi transformada em seçāo anexa ao mesmo, juntamente com a Numismática e

tes a redação da revista do IHGB mostrava adesão a Rousseau no publicar a Ode ao Homem Selvagem de Pereira Caldas, escrita eln 1794, após a leitura e em homenagem ao filósofo francês, coıno diziàn eın noia de pé-de-página (RIHCB. 2 (1840), p. 131 ). Buffon e outros téricos naturalistas eram frequentemente citados pelos autores. 
a Arqueologia (CASTRO FARIA, 1949, p. 8). Porém, ainda se constituia numa parte importante das exposiçōes daquela instituição como bem demonstrou o seu diretor, cvidenciando que era um dos aspectos das ciências naturais que apresentava demanda social e/ou política.

\section{Conclusāo}

As iniciativas políticas tomadas naquela ćpoca no Brasil, ao que se sabe poucos resultados econômicos frutificaram, pois a agricultura do país continuou baseada na agro-exportação dos produtos litorâneos em que o café exerceu o papel mais importante. Porém, do ponto de vista científico os resultados obtidos foram maiores, pois, a natureza do Brasil que era motivo da cobiça por parte de naturalistas e de países do mundo inteiro desde os tempos do descobrimento, ganhou o status nacional. Como disse um dos sócios do IHGB em 1854:

Deus me fez nuscer neste paraiso. é porque desejo vê-lo es. tudado e inventariado por Brasileiros. (Revista do IHGB. 17 (J854). p.57).

Das relaçōes entre as ciências naturais e a política de construção da nação emprecndida pelo governo imperial brasileiro naqueles anos de meados do século XIX, pode-se depreender que, embora as ciências não decorrcssem da política a dimensão que clas alcançaram foi conseqüência da iniciativa e do incentivo da política do Estado. As características físicas do Brasil e a pluralidade de sua composição social que já eram objeto de estudos de naturalistas estrangciros

\section{Bibliografia}

AGASSIZ. L. Journey in Brazil. Cambridge University Press. edição de 1909, $1^{2}$ ediçūo 1867. Viagem an Brasil. Rio de Janciro, Companhia Editora Nacional. ou brasileiros, passaram a ser também objeto da politica de construçāo da nação. Tal fato parece ter contribuído decisivamente para a institucionalização de diferentes ramos das ciências naturais no país. Neste sentido, as ciências naturais não somente implementavam a construção da nação, como ganharam dimensōes nacionais e, assim, a natureza do país dcixou de ser um apátrida objeto científico.

Não somente o inventário dos recursos naturais do país intcressava, mas este cra também importante para o comércio daqueles produtos que adquirissem demanda. Na segunda metade do século XIX, quando o capitalismo instituiu a sua grande vitrinc, isto é, multiplicou as exposiçōes internacionais, o Brasil delas passou a participar ativamente, expondo os produtos nativos provenientes do seu interior. Mostrava ao mundo, através da divulgação dos relatórios de viagens e de scus especialistas em ciências naturais a viabilidade da exploração das suas riquezas e do povoamento do seu interior. O Brasil, da segunda metade do século XIX. já não oferecia ao mercado externo apenas alguns produtos tropicais que produzia em larga cscala, mas colocava toda a sua geografía botânica e zoológica na vitrine.

O casamento entre as ciências naturais $\mathrm{e}$ a política que o governo imperial emprecndeu $\mathrm{cm}$ meados do século contribuiu para promover a integração territorial do lmpério e fazer a unidade político-nacional do Brasil, tanto quanto contribuiu para institucionalizar aspectos científicos novos e ainda muito pouco cstudados, tal como a geografia, a geologia, a astronomia ou a etnografia, ou para reafirmar a importância da botânica $\mathbf{e}$ da zoologia naquele contexto político.

AVE-LALLEMANT, R. Viugem pela Província do Rio Grande do $S u l(1858)$. Belo Horizonte, Ed. Liatiaia, 1980.

BASTOS. W. de L. Engenheiro Hentrique Halfeld, satu vida. sua 
obra, sua descendência. Juiz de Fora, MG, Ediçőes Paraibuna, 1975.

CASTRO FARIA. L. de. As Exposiçöes de Antropologia e Arqueolugia do Museu Naciomal. Rio de Janciro, Depatamento dc Imprensa Nacional, 1949.

CELl.ARD, J. Ah' Ca ira. Car ira ... . Paris. Balland. 1979.

Coleção de Documentos do Arquivo Adıninistrativo, Histórico. Científico do Museu Nacional (AAHC-MN)

COSTA LIMA. L. O Comtrole do Imagimário. Săo Paulo. Brasiliense. 1984.

DANTES, M.A.M. Institutos de Pesquisa Científica, em MOTYAMA,S. \& FERRI. M.G. Histúria das Ciências no Brasil. São Paulo, EDUSP/EPU, 1979/80,v.2.

DIAS, M.O. da S. "A lntcriorização da Metrópole" in MOTA, C.G. (org.). 1822 Dimensĩes. 2 ediçio, São Paulo, Perspectiva, 1986, Coleçāo Debates.

DOMINGUES, H.M.B. A Noşăo de Civilizașüo na Visäo dos Construtores do limperio. A Revista do /HCB. 1838-150/60. Niterói, Dissertaç̄o de Mestrado, 1990.

DOMINGUES, H.M.B. Ciência: um Caso de Políica. As relaçōes entre as Ciências Naturais e a Asricuhtura no Brasil Império. São Paulo, USP. Tese de Doutoramento, 1995.

DUCHET, M. Les parages des Saroirs. Paris, Edition La Découverte, 1985.

FIGUEIROA, S.F. de M. A Comissino Geológica do Império. IG/
UNICAMP (Irabalho mimeografado).

FURET. F. L'Atelier de I'Histoire. Paris, Flammarion, 1982.

HOLANDA. S.B. dc. Caminhos e Fronseiras. $3^{3}$ edição, São PauJo, Comanhia das Letras, 1994.

KATYNSKI, J.R. "Ferrovias Nacionais". MOTOYAMA. S. (org.). Techologia e Ithdustrializas:äo no Brusil. São Paulo, UNESP/ CEETEPS, 1994.

MARQUES DOS SANTOS. A.C. No Rascumho da Naçäo: Inconficência no Rio de Jameirr. Rio. Secretaria Municipal de Cultura. Turismo e Esportes, 1992. Coleção Biblioteca Carioca.

PATY, M. L'Analise Critique des Sciences. Paris, L'Harmattan, 1990.

PLUMYÈNE, J. Les Natons Romantiques. Paris, Fayard, 1979.

Relatônios Anuais do Ministério da Agricultura. Comércio e Obrus Piblicas - MACOP (1860-1889)

Relatorios Anuais do Ministério dos Negócios do Império (Anos $18.50)$.

Revishas do Instituto Historico e Geografico Brasileino (18381860).

SIMONSEN, R. História Econômica do Brasil (1500//820). $8^{2}$ edição, São Paulo, Companhia Editora Nacional, 1978.

Trabalhos da Comissǟo Cienifica. Rio de Janeiro, Typ. Universal Laemmert. 1862.

VARNhAGEN, F. Histivia Geral do Brasil. la ediçĩo, Rio de Janciro. Editora Latemment. 1854.

Endereço da Autora: Rua Joaquim Campos Porto, 278 • CEP 22460-190 • Rio de Jantiro • RJ • Brasil • Fax (021) 512-4483 